Sahadevan, V., and Varghese, K. (2019). "AHP and CBA Application to Layout Design: A Case of Classroom Layout Assessment" In: Proc. 27 $7^{\text {th }}$ Annual Conference of the International. Group for Lean Construction (IGLC), Pasquire, $C$ and Hamzeh FR (Ed). Dublin, Ireland, pp. 1333-1344. DOI: https://doi.org/10.24928/2019/0256. Available at: 〈www.iglc.net>.

\title{
AHP AND CBA APPLICATION TO LAYOUT DESIGN: A CASE OF CLASSROOM LAYOUT ASSESSMENT
}

\author{
Vijayalaxmi Sahadevan ${ }^{1}$ and Koshy Varghese $^{2}$
}

\begin{abstract}
Arriving at a consensus in design decisions is challenging owing to the presence of diverse and multidisciplinary stakeholders with multiple design objectives. The literature on AEC design decision making have reported Analytic Hierarchy Process and Choosing by Advantages as two commonly used multi-criteria decision-making techniques for evaluation of design alternatives. However, the existing literature has mainly focused on choosing between material or technology and the comparison of the two techniques to assess the suitability for their application to non-spatial aspects of AEC design problem. The current work seeks to investigate the suitability of CBA and AHP to a layout design problem. A decision-making exercise involving a hypothetical case of evaluation of three classroom layouts was conducted. A set of criteria for design evaluation which was derived based on a previous study on stakeholder design values was used in the exercise. Conclusions were drawn based on the operationalization of the two techniques rather than a direct comparison of the results obtained from the two techniques.

The findings from the study indicate that CBA aids in defining a robust set of design criteria, sub-criteria and attributes and facilitates a collaborative decision-making process. On the other hand, AHP provides a structured approach for eliciting individual participant judgments. The benefits and limitations with respect to the operationalization of the two techniques are discussed in detail.
\end{abstract}

\section{KEYWORDS}

Choosing by advantage (CBA), set based design (SBD), analytic hierarchy process (AHP) and target value design (TVD)

\section{INTRODUCTION}

The requirement definition phase of Architecture, Engineering and Construction (AEC) designs is typically complex in nature involving tacit information and multiple decision points. Arriving at a consensus in design decisions is challenging owing to the presence of

1 Doctoral Student, Dept. of Civil Engineering, Building Technology and Construction Management, Indian Institute of Technology Madras, India, svijaya16@gmail.com

2 Professor, Dept. of Civil Engineering, Building Technology and Construction Management, Indian Institute of Technology Madras, India, koshy@iitm.ac.in 
diverse and multidisciplinary stakeholders with multiple and conflicting objectives. Design values can provide motivational, broader range and long- term goals for AEC design and these values can further aid as criteria in decision making.

Lean philosophy bases its foundations on value maximization and waste minimization. Further, lean literature discusses value in AEC design in a number of contexts such as the Transformation Flow Value (TFV) theory (Koskela 2000), Target Value Design (TVD), Choosing by Advantages (CBA), etc. Although the concept of value has been reiterated in the lean literature, a common definition and categorization of design values have not emerged.

Prior studies on value-based design decision making have mainly focused on MultiCriteria Decision Making (MCDM) techniques and their suitability to AEC design problem. CBA is an MCDM technique which has been applied to a range of choice problems. In material selection problem, CBA has been applied in choosing between rebar for beamcolumn joint (Parrish and Tommelein 2012), exterior wall assembly (Arroyo et al. 2012), ceiling tiles (Arroyo et al. 2013; Arroyo et al. 2016), insulation material (Arroyo et al. 2015) etc. Other applications include selection of bidder in public-sector (Schottle et al. 2017), fall protection system (Karakhan et al. 2016), etc. Similarly, the technique of AHP has been applied to problems such as the selection of equipment for construction (Shapira and Golderberg 2005), assessment of pipeline design (Dey 2003), etc.

Arroyo et al. (2014), Arroyo et al. (2015) and Parrish et al. (2015) argue that CBA technique is superior to Analytic Hieararchy Process (AHP) in the context of AEC design based on comparative studies between the two techniques. In the aforementioned studies, several factors related to the operations involved in both the techniques were used to highlight the advantages of CBA over AHP using the example of a material selection problem. The key advantages included context specificity and transparency. In addition, a few technical limitation of AHP were discussed.

In the current study, preferences between layout needs to be assessed. The characteristics of layout selection are different from material and technology selection problem. In Layout selection a user is concerned with experience within the space and this experience in relation to the space is difficult to visualize. As a result the outcomes from the options are intangible in nature due to which the evaluation of layout needs to be done using abstract criteria. Therefore, the study of the effectiveness of the application of the two MCDM techniques for evaluating spatial design needs further exploration.

A study on stakeholder values in the design of university campus buildings (Sahadevan and Varghese 2018), led to a framework for evaluating design alternatives. The framework proposes the use of MCDM technique by using stakeholder values as criteria for design decision making. The decision problem in the above study was concerned with assessing layout design alternatives. However, before applying the framework to a campus layout level, it was decided to conduct a smaller scale study to assess the suitability of the two techniques to a layout problem.

The objective of the paper is to study the suitability of the two techniques to a classroom layout design problem. The study does not attempt to compare the rankings obtained from the two techniques, but rather draws its insights from the observations made during the operationalization of the techniques. 
The next section of the paper summarizes the AHP and CBA techniques. The paper then discusses the methodology adopted for the current study and the outcomes of the study followed by discussion and conclusions section.

\section{AHP AND CBA METHODOLOGY}

\section{ANALYTIC HIERARCHY PROCESS}

AHP is a widely used MCDM technique applied in various areas in deciding between solution alternatives. AHP is a mathematical tool which requires decision makers to provide pairwise comparisons at each criterion level to arrive at weights for each criterion. AHP is particularly useful in cases of conflicting criteria and can consider both subjective and objective criteria for decision making (Saaty 1980). This is the basic advantage of using AHP over cost-benefit analysis, as criteria with different units can be used for comparison, unlike cost-benefit analysis where all criteria have to be in monetary terms. The technique aids in arriving at an optimum solution considering the various criteria.

The technique of AHP is found to be suitable for this problem due to the presence of conflicting design criteria in the design evaluation problem. The other advantage of using AHP is that it does not require a statistically significant sample size. The use of expert data in AHP analysis can be representative of a group in the sample data (Golden et al. 1989). Figure 1 summarizes the steps involved in the framework.

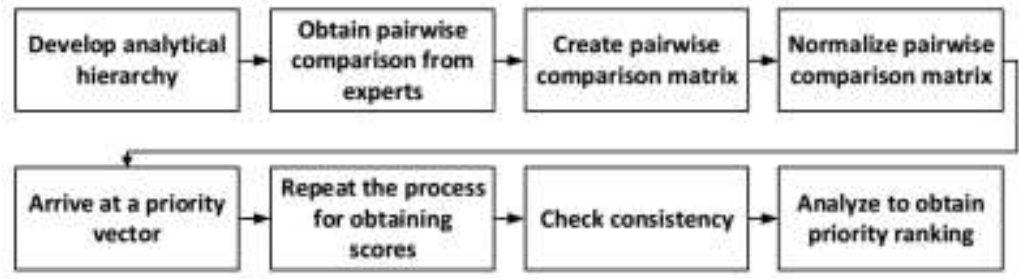

Figure 1: Steps in AHP

In AHP, a decision problem is decomposed into a hierarchy of criteria and alternatives. The information is arranged in an analytic hierarchy. The AHP operation yields relative rankings of the alternatives.

\section{Choosing BY ADVANTAGES}

Lean literature advocates CBA for design decision-making problems. CBA was developed by Jim Suhr (1999) to compare the advantages of alternatives. The technique is based on criteria of alternatives and stakeholder preferences for the advantages. CBA consists of a tabular method for choosing between mutually exclusive alternatives with unequal costs.

The CBA vocabulary includes the terms alternatives, factor, criterion, attribute, and advantage. The meanings of the above terms are as follows:

- Alternative - a possible decision

- Criteria - a decision rule or guideline as per decision makers

- Attribute - a characteristic or quality

- Factor - a container for criteria, attribute, advantages, importance and other types of data (Suhr, 1999) 
The steps involved in CBA are as summarized in Figure 2 (Arroyo 2014):

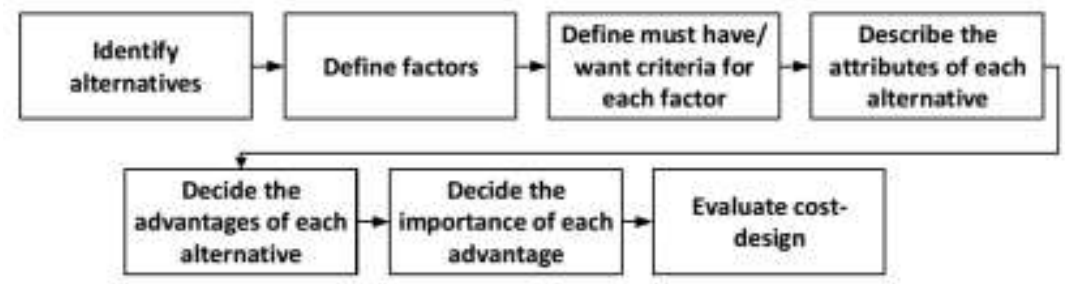

Figure 2: CBA steps

For CBA implementation a group of relevant stakeholders who influence the design needs to be selected who will be the decision makers in the process.

\section{CRITERIA FOR LAYOUT EVALUATION}

The application of MCDM necessitates a systematic identification of criteria for decision making. The set of design values from a previous study on university campus design (Sahadevan and Varghese 2018) were used as criteria for applying the two techniques. The criteria of constructability and schedule were not considered in this study as the influence of these criteria on the classroom layout decision was assumed to be insignificant. Table 1 summarizes the design criteria that were used for the study.

Table 1: Design Criteria

\begin{tabular}{|l|l|l|}
\hline Sr. No. & Design Criteria & Description \\
\hline 1 & Functional & $\begin{array}{l}\text { Provision of all types of requirements, acoustics, efficient planning of spaces, } \\
\text { availability of charging points }\end{array}$ \\
\hline 2 & Image & The visual appeal of the design \\
\hline 3 & Sustainable & The embodied energy of materials used in construction \\
\hline 4 & Social & Opportunities created for interaction among users \\
\hline 5 & Flexible & Ease of converting the space for a different utility purpose \\
\hline 6 & Design quality & Efficient utilization of available spaces or functional efficiency \\
\hline 7 & Health & Ergonomic considerations \\
\hline
\end{tabular}

Figure 3 illustrates the hierarchical framework for AHP analysis for single criteria level problem.

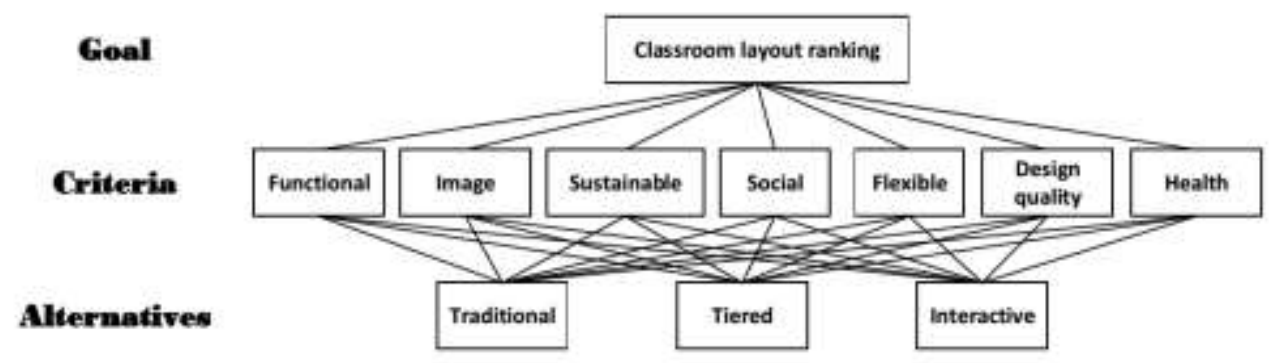

Figure 3: Analytic Hierarchy at three levels

\section{RESEARCH METHOD}

The aim of the current work is to assess the suitability of AHP and CBA to layout design evaluation based on their operationalization to a classroom layout problem. The problem was concerned with design layouts for post-graduate courses for an engineering institute. Three layout alternatives were developed whose features are summarized in Table 2. 
Table 2: Features of the three layout alternatives

\begin{tabular}{|l|l|l|l|}
\hline \multicolumn{1}{|c|}{ Category } & \multicolumn{1}{c|}{ Layout 1 } & \multicolumn{1}{c|}{ Layout 2 } & \multicolumn{1}{c|}{ Layout 3 } \\
\hline Type of classroom & Traditional & Tiered & Interactive \\
\hline Capacity (seater) & 42 & 45 & 45 \\
\hline Area (sq.m.) & 119 & 110 & 141 \\
\hline Cost (₹) & $6,95,000$ & $12,57,000$ & $8,00,000$ \\
\hline Embodied Energy (GJ) & 1401 & 2995 & 1123 \\
\hline Reverberation time (s) & 0.34 & 0.28 & 0.5 \\
\hline
\end{tabular}

It was assumed that the classrooms were designed for engaging courses which are conceptual and discussion oriented for a class strength of a maximum of 40 students. The location of the building housing the classroom was assumed to be Chennai-India for all the three alternatives. A Revit model (Figure 4) was developed for the three design solutions which aided in visualization as well as material take-offs.

a.

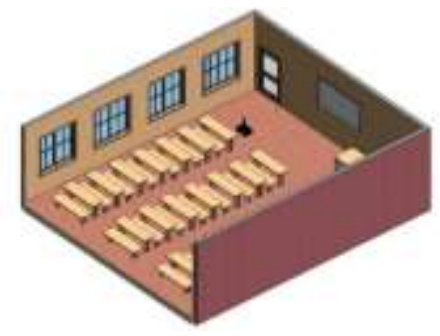

b.

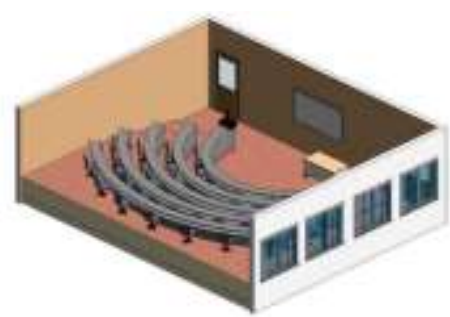

c.

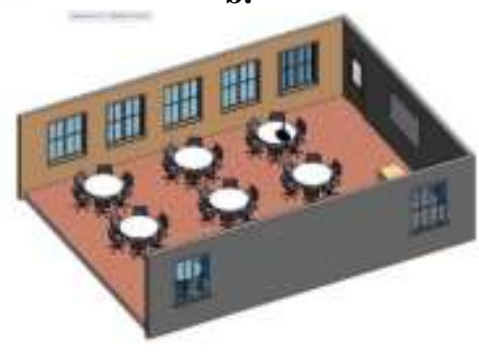

Figure 4: Revit model of the three layouts a. Traditional, b. Tiered and c. Interactive The total cost for construction of the classroom and the energy footprint was calculated from the model. The embodied energy values were considered from the Inventory of Carbon and Energy (Hammond and Jones 2008) for construction materials for arriving at the energy footprint. The reverberation time was used as an indicator for the acoustic performance of the classrooms. The reverberation time was calculated using Sabine's reverberation equation and was found to be within permissible limits for all the three alternatives (Sabine 1964).

Since the study did not aim to compare the results obtained from the two studies, the research design did not necessitate conducting both the exercises with a single group. On the contrary, this avoided the participants from getting influenced by the judgments made from a previous exercise. The following broad steps were used to conduct the study:

i. Four experienced faculties were chosen for the AHP exercise whereas a group of $17 \mathrm{Ph} . \mathrm{D}$. scholars participated in the CBA exercise.

ii. Both the groups were briefed with the design features of the three alternatives and subsequently, each participant was asked to rank their layout preference based on individual ad-hoc judgment. 
iii. The participants were familiarized with the CBA and AHP vocabulary and procedures.

iv. The participants were asked to list down and discuss the criteria with which they would evaluate the layout of the classroom.

v. AHP / CBA sessions were conducted individually for the AHP and as a group for CBA. The session was audio recorded for analysis after the study. The AHP analysis was done using a standard commercial software.

One of the challenges in AHP implementation was obtaining consistency in the data. AHP data with an inconsistency above $10 \%$ cannot be considered for analysis forcing the researcher to either repeat the process with the particular participant or altogether eliminate the data point. The major challenge in conducting the CBA exercise was co-locating all the decision makers. The findings from the two exercises are discussed in the next section.

\section{RESULTS}

Prior to starting the exercise, a brainstorming exercise was conducted to identify whether the identified criteria (Table 1) were comprehensive enough for evaluating the design alternatives. The discussion did not yield any additional criteria other than the ones mentioned in Table 1.

\section{AHP RESULTS}

Table 3 summarizes the rankings given by the four respondents for the three alternatives based on individual ad-hoc judgment.

Table 3: Individual judgment

\begin{tabular}{|c|l|l|l|}
\hline Decision Maker & Rank 1 & Rank 2 & Rank 3 \\
\hline Faculty $\mathbf{1}$ & Tiered & Interactive & Traditional \\
\hline Faculty $\mathbf{2}$ & Tiered & Traditional & Interactive \\
\hline Faculty $\mathbf{3}$ & Interactive & Traditional & Tiered \\
\hline Faculty $\mathbf{4}$ & Tiered & Traditional & Interactive \\
\hline
\end{tabular}

The outcomes of this rankings indicate that majority of the faculty (three out of four) preferred tiered classroom over the other two options and three out of four faculty gave rank 2 to the traditional classroom. The results in the form of scores obtained from the AHP analysis are summarized in Table 4.

Table 4: AHP scores

\begin{tabular}{|l|l|l|l|}
\hline & Traditional & Tiered & Interactive \\
\hline Faculty 1 & 0.280 & 0.332 & $\mathbf{0 . 3 8 8}$ \\
\hline Faculty 2 & 0.275 & 0.315 & $\mathbf{0 . 4 1}$ \\
\hline Faculty 3 & 0.07 & $\mathbf{0 . 7 0 7}$ & 0.223 \\
\hline Faculty 4 & $\mathbf{0 . 7 4 2}$ & 0.183 & 0.075 \\
\hline
\end{tabular}

Inconsistency in all the four cases were below 10\%. The AHP scores indicate that AHP yielded different rankings compared to the individual judgments. For example, faculty 1 and 2 preferred tiered classroom over the other two based on individual judgment. However, the AHP exercise resulted in the interactive classroom as rank 1 in both the cases. Similarly, as per the AHP score faculty 3 gives high preference to tiered classroom although the faculty had given rank 1 to interactive classroom and rank 3 to tiered classroom based on ad-hoc judgement. Faculty 4 ranked the three classrooms in the order of tiered over traditional over interactive however the AHP analysis indicates high preference to 
traditional classroom. The reasons for this variation from the individual judgement is discussed in the discussion section.

\section{CBA RESULTS}

Figure 5 summarizes the rankings given by the participants based on individual ad-hoc judgment.

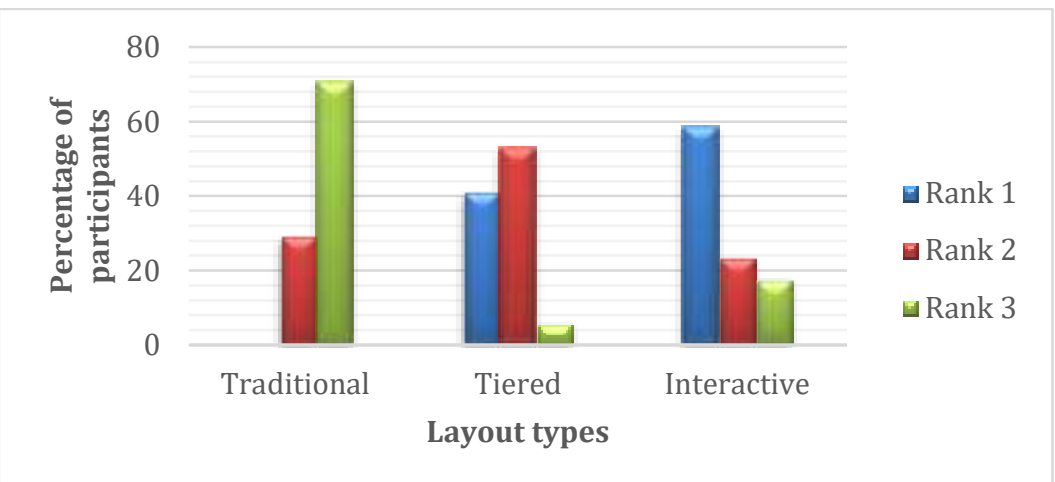

Figure 5: Rankings based on individual participant intuition

$58.8 \%$ of the participants gave rank 1 to interactive classroom, whereas the remaining $41.2 \%$ gave tiered classroom rank 1. Almost $70 \%$ of the participants gave rank 3 to traditional classroom. From the results, it can be said that the majority of the participants prefer interactive over tiered and traditional classroom. As all the participants are $\mathrm{Ph}$. D. students, these judgements are predominantly from the user perspective.

CBA Table:

The following Table summarizes the CBA exercise.

Table 5: CBA summary

\begin{tabular}{|c|c|c|c|c|c|c|}
\hline Vactors & \multicolumn{2}{|c|}{ Alt.t: Traditional } & \multicolumn{2}{|c|}{ All.2: Tiered } & \multicolumn{2}{|c|}{ Alt.3: Interactive } \\
\hline \multirow{2}{*}{$\begin{array}{l}\text { 1. Functional } \\
\text { ia. Provibas of all clabossum } \\
\text { requirements } \\
\text { Crit: Hether is belter }\end{array}$} & \multicolumn{2}{|l|}{ Alt Pronided } & \multicolumn{2}{|l|}{ Att: Provised } & \multicolumn{2}{|l|}{ AIt: Ptonided } \\
\hline & Adv $:$ & 10fA: & Adv: & InfA: & Adv: & IotA: \\
\hline \multirow{2}{*}{ 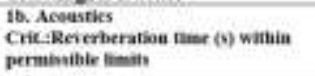 } & \multicolumn{2}{|c|}{ At 0.34 (Withia permissitie limes) } & \multicolumn{2}{|c|}{$\begin{array}{l}\text { Ant: } 0.28 \text { (uiftin permassitle } \\
\text { finis) }\end{array}$} & \multicolumn{2}{|c|}{ At: 0.3 (within permisible limits) } \\
\hline & Adv: $:$ & Toth: & Aat: : & loth: & Ady: & tot $A:$ \\
\hline \multirow{2}{*}{ 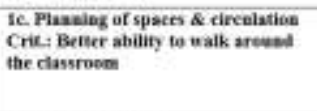 } & \multicolumn{2}{|l|}{ Art: soine circulatioe spase } & \multicolumn{2}{|c|}{ Att: Less cusulationspace } & \multicolumn{2}{|l|}{ Ant. Mose cieculation space } \\
\hline & $\begin{array}{l}\text { Adv : Souse esse for wen } \\
\text { to move arousd in the } \\
\text { clrospom. }\end{array}$ & Jofa:20 & Aath:i & IUfA & 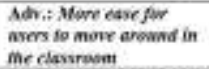 & IOEA:A00 \\
\hline \multirow{2}{*}{ 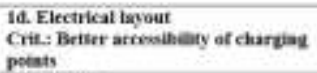 } & \multicolumn{2}{|l|}{ AII. Adequate avcessitulity } & \multicolumn{2}{|c|}{ Ant: Adeq-wee accecobsility } & \multicolumn{2}{|l|}{ Ar Adequate ascessibility } \\
\hline & Antve & lafa: & Ant: & IotA & Adv. & TofA: \\
\hline \multirow[t]{2}{*}{$\begin{array}{l}\text { 2. Image } \\
\text { Cris: More avpeniling is betier }\end{array}$} & \multicolumn{2}{|c|}{ At seme adety anaygemedt } & \multicolumn{2}{|l|}{ Ant: Ondetly } & \multicolumn{2}{|c|}{$\begin{array}{l}\text { Arr Lest wpealing could ge } \\
\text { divardety }\end{array}$} \\
\hline & Adv = Less visual appesl & $\operatorname{lot} A=30$ & $\begin{array}{l}\text { Advi: nonals } \\
\text { aproding }\end{array}$ & toth90 & Ady: & 1ot $\Omega$ : \\
\hline \multirow{2}{*}{$\begin{array}{l}\text { 3. Sustainahle } \\
\text { Crit.. Fimbodied Energy (G)). } \\
\text { lower is better }\end{array}$} & \multicolumn{2}{|l|}{ Ant 1001} & \multicolumn{2}{|l|}{ An! 2005} & \multicolumn{2}{|l|}{ Ant: 1123} \\
\hline & Adv $=1594$ & Jofa 50 & Ach: : & $\operatorname{lofA}$ & Adv $t \sqrt{672}$ & IofA 60 \\
\hline \multirow{2}{*}{$\begin{array}{l}\text { 4. Design quality } \\
\text { Crit:- More the area (sq- m.) was } \\
\text { considered better for the user }\end{array}$} & \multicolumn{2}{|l|}{ Aft 119} & \multicolumn{2}{|l|}{ Att Lil } & \multicolumn{2}{|l|}{ Att $14 \mathrm{II}$} \\
\hline & Adv- 5 & Tafac 30 & Aat:! & IOFA & Adv $: 3$ & Iofasos \\
\hline \multirow{2}{*}{$\begin{array}{l}\text { 5. Social } \\
\text { Cre: Higher interaction } \\
\text { oppornuaities are betser }\end{array}$} & \multicolumn{2}{|c|}{ 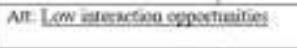 } & \multicolumn{2}{|c|}{ 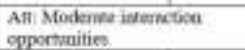 } & \multicolumn{2}{|c|}{ An: High imarnetice opoothnziet } \\
\hline & Advi & lofi: & $\begin{array}{l}\text { Aht: Somentiat } \\
\text { social }\end{array}$ & lof $A-50$ & Adv: BSore social & IotAso \\
\hline \multirow{2}{*}{$\begin{array}{l}\text { 6. Flexible } \\
\text { Crit: Ease of future adaptability } \\
\text { to changes, higher is better }\end{array}$} & AIr Cal be madifief with: & catie ense & Ant: Candot te ad & int sasti: & $\begin{array}{l}\text { Arr Cal be rasdified woth } \\
\text { ence }\end{array}$ & greiber \\
\hline & $\begin{array}{l}\text { Adv - Sounewhat } \\
\text { gdsptable }\end{array}$ & $\operatorname{lof} A-40$ & Aak: $:$ & lofe & 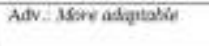 & lofases \\
\hline
\end{tabular}


In the CBA exercise, the criterion of ergonomics was not considered as the group was not able to arrive at a consensus on objective attributes for judging the alternatives due to the subjective nature of the criteria. The advantage of ease of circulation was considered as the paramount advantage. The results of the CBA exercise are summarized in Figure 6.

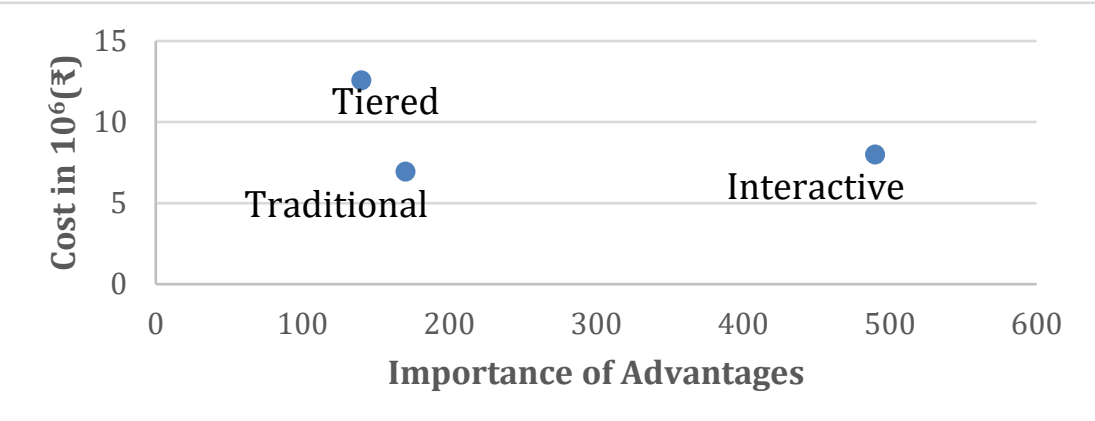

Figure 6: Cost v/s IofAs

As can be observed from the graph, the interactive classroom has the highest IofA of 490 with a cost of ₹ 8,00,000. The traditional classroom has an IofA of 170 with the least cost of ₹ 6,95,000. Both individual rankings and the CBA outcomes show that the group preferred interactive classroom over the other two alternatives. The IofA of the interactive classroom is way higher compared to the other two alternatives. Further, the cost - IofA graph indicates that although the traditional classroom cost is least among the three, the interactive classroom is the best option as an increase in cost by ₹ 10,50,000 yields advantages which is more than twice of the traditional one.

As the exercise was conducted for a hypothetical case, participants were required to provide inputs based on knowledge and experience. It goes without saying that practitioners as participants in the study would provide realistic inputs in terms of criteria and attributes as opposed to non-practitioners due to lack of on-field experience which is the limitation of the study. Another limitation was the presence of a large group (17 members in the case of CBA) which can lead to chaos affecting the decision-making process as opposed to a smaller group which is easier to control.

\section{DISCUSSION AND CONCLUSIONS}

\section{Role of individual preferences in decision making:}

As discussed earlier the AHP scores indicated variation in the faculty rankings between the ad-hoc opinion of faculty and their AHP computed preference. The AHP scores of faculty 1 and faculty 2 indicate their preference towards interactive type of classroom in contrast to their ad-hoc opinion in which both the faculty gave rank 1 to tiered type of classroom. As per the AHP scores, the interactive classroom scored high due to the 'social' and 'flexible' criteria. Both faculty 1 and 2 handle courses which are pedagogically interactive and involves group discussion. The AHP process ensured that the individual preference of the decision makers for all the criteria is elicited thereby ensuring a more holistic representation of their actual preference.

The variation in the judgments of faculty 3 and 4 can also be similarly explained. Although, faculty 3 gave rank 1 to interactive classroom, the AHP score indicates high preference 
towards tiered type of classroom. This was due to the high weightage given by the faculty to 'functional' and 'image' criteria. The faculty predominantly engages in lecture-based courses which does not involve student interaction. Faculty 4, gave rank 1 to tiered classroom during ad-hoc judgment but showed high preference towards traditional classroom. Faculty 4 also engages in lecture-based courses which does not involve group activities.

Upon discussions with the faculty, it was revealed that the faculty gave ad-hoc judgment depending upon the type of courses they handle and other factors such as the ease of control of the audience. From the AHP analysis it was observed that the criteria of 'social' and 'flexible' influenced the final outcome of the process which were not considered during the ad-hoc judgment. The AHP process required that the faculty give their preferences for all criteria mentioned in Table 1 aiding in the inclusion of all relevant criteria in decision making.

\section{Soundness of decision making:}

The soundness of the two techniques in layout decision making are discussed below using four important factors reported by Arroyo et al. (2015).

- Consistency: Arroyo et al. (2015) have discussed how removal of certain nondifferentiating criteria can lead to rank reversal in AHP. It goes without saying that CBA is beneficial with respect to this factor. However, there is no explanation in the existing literature concerning the quality of decision by AHP if only differentiating criteria are used. The question whether AHP decision can be made more sound by considering only differentiating factor needs further exploration.

- Context- specific: Arroyo et al. (2015) discuss the limitation of AHP citing that factors' weights are obtained from experts without specific alternatives. While CBA process is solely based on context specific attributes, AHP weights in the current work were obtained by considering the available alternatives which makes the judgment context specific.

- Transparency of trade-offs within and among factors: Arroyo et al. (2015) discuss about linear trade-offs in AHP operations being unrealistic when concerned with criteria which do not exhibit linear increments of performances. CBA on the other hand is not dependent on such assumptions. These assumptions are certainly a draw-back of AHP and better methods of choosing criteria and eliciting preferences needs to explored.

- Subjectivity: In the current work it was found that agreeing on advantages for a subjective criterion such as image was a challenge as there were strong and clear differences in the opinion of participants.

Some additional factors from the current study are summarized below.

- Collaboration and transparency: While, the use of AHP in the current work illustrated how individual preferences influence decision making, CBA facilitated collaborative and transparent decision making which is a necessity in design decision-making. However, the dynamics of the decision-making group has an 
influence on the time and effort expended in reaching a consensus on attributes as well as on individual IofAs. In typical design situations where diverse stakeholders are trying to maximize their objectives, it can be challenging to arrive at a consensus. As the scale of the problem increases, so does the complexity of the design attributes rendering the technique even more challenging to implement. In case of AHP, aggregation of individual judgments for arriving at group consensus and its influence on design decision making needs further exploration.

- Abstractness of criteria: An important criterion in the layout of the classroom and furniture layout is ergonomics. Due to the subjective nature of this criterion, obtaining consensus on advantage and importance of advantages is challenging.

Ease of operationalizing of the techniques: As the AHP technique involves obtaining individual preferences and scores, the participants need not be co-located and the individual judgements can be aggregated to analyze the group judgement. After the initial brief, the participants took ten to fifteen minutes in eliciting the weights and scores. The CBA exercise is collaborative and necessitates the co-location of all decision makers involved with the design. The CBA exercise took three hours which was much longer compared to the time spent by a participant in AHP. Thus, it can be stated that AHP can be operationalized with relative ease as opposed to CBA wherein the decision makers are required to invest more time and effort. However, in the current study the longer time taken to arrive at a decision can be attributed to the larger size of the group (17 members) involved in the exercise.

\section{CONCLUSIONS}

From the discussions, it can be concluded that AHP aids in capturing individual preferences in design decision making. AHP was found to be easier to implement in case of subjective and abstract criteria. Although, AHP is based on individual judgment it provides structure to decision making and hence it is easier to operationalize. The disadvantages of AHP with regards to consistency and trade-offs call for further exploration. In order to make informed decisions, it is essential that design decisions are made collaboratively. CBA allows decision makers to arrive at sound criteria and sub-criteria and indulge in collaborative and transparent decision making. In order to have a fair comparison between the two techniques similar number of participants is warranted which is a limitation of the study.

\section{FUTURE WORK}

The benefits of both the techniques need to be harnessed to arrive at a robust method for layout design evaluation. Therefore, a CBA-AHP framework which combines the characteristics of the two techniques needs to be explored further.

\section{REFERENCES}

Arroyo, P., Ballard, G. \& Tommelein, I.D. (2014) "Choosing By Advantages and Rhetoric in Building Design: Relationship and Potential Synergies" In:, Kalsaas, B.T., Koskela, 
L. \& Saurin, T.A., 22nd Annual Conference of the International Group for Lean Construction. Oslo, Norway, 25-27 Jun 2014. pp 391-408

Arroyo, P., Tommelein, I. D. and Ballard, G. (2013) 'Using 'Choosing by Advantages' to Select Tile From a Global Sustainable Perspective" In:, Formoso, C.T. \& Tzortzopoulos, P., 21st Annual Conference of the International Group for Lean Construction. Fortaleza, Brazil, 31-2 Aug 2013. pp 309-318

Arroyo, P., Tommelein, I. D. and Ballard, G. (2014) "Comparing AHP and CBA as Decision Methods to Resolve the Choosing Problem in Detailed Design" Journal of Construction Engineering and Management, 141(1).

Arroyo, P. Tommelein, I. D. and Ballard, G. (2016) "Selecting Globally Sustainable Materials: A Case Study using Choosing by Advantages", Journal of Construction Engineering and Management, 141(2).

Cao, W., Sheng, Y. and Qin, Y. (2009) "AHP for the assessment of permafrost environment in Muli mining are of Qinghai Province, China." Proc., 14th Conf. on Cold Regions Engineering, Duluth, MN, 201-211.

Dey, P. K. (2003) "Analytic Hierarchy Process Analyzes Risk of Operating Cross-country petroleum pipelines in India" Natural Hazards Review, 4(4): 213-221.

Golden, B., Wasil, E., and Harker, P. (eds) (1989) "The Analytical Hierarchy Process: Applications and Studies." Springer Verlag, New York.

Hammond, G. and Jones, C. (2008) "Inventory of Carbon \& Energy" Sustainable Energy Research Team (SERT), Department of Mechanical Engineering, University of Bath, UK.

Koskela, L. (2000) "An exploration towards a production theory and its application to construction." VTT Technical Research Centre of Finland, VTT Publication 408.

Parrish, K. \& Tommelein, I.D. (2009) "Making Design Decisions Using Choosing by Advantages" In:, Cuperus, Y. \& Hirota, E.H., 17th Annual Conference of the International Group for Lean Construction. Taipei, Taiwan, 15-17 Jul 2009. pp 501510

Saaty, T. L. (1989) “The Analytic Hierarchy Process: Planning, Priority Setting, Resource Allocation" McGraw-Hill, New York.

Sabine, W. C. (1964) "Collected Papers on Acoustics" Harvard U. P., Cambridge, MA, 1922; reprinted by Dover, New York, 1964.

Sahadevan, V., and Varghese, K. (2018) "Stakeholder Value Evolution, Capture and Assessment in AEC Project Design." In: Proc. 26th Annual Conference of the International Group for Lean Construction (IGLC), González, V.A. (ed.), Chennai, India, pp. 549-559.

Shapira, A. and Goldernberg, M. (2005) "AHP-Based Equipment Selection Model for Construction Projects" Journal of Construction Engineering and Management, 131(12): 1236-1273.

Suhr, J. (1999). "The choosing by advantages decision-making system." Quorum, Westport, CT, 304. 
Sahadevan, V., and Varghese, $K$

1344

Proceedings IGLC - 27, July 2019, Dublin, Ireland 